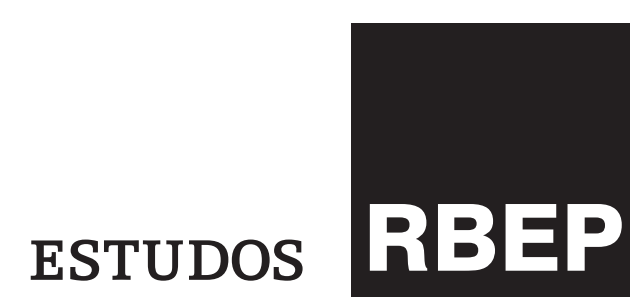

\section{Políticas de inserção profissional na rede municipal de ensino do Rio de Janeiro: uma proposta em movimento}

\author{
Maria das Graças Chagas de Arruda Nascimento ${ }^{\text {I, II }}$ \\ Maria José Batista Pinto Flores ${ }^{\mathrm{III}}$ IV \\ Yrlla Ribeiro de Oliveira Carneiro da Silvav, vi
}

http://dx.doi.org/10.24109/2176-6681.rbep.100i256.4128

\section{Resumo}

Este artigo apresenta resultados de uma pesquisa que analisou as ações propostas pela rede municipal de ensino do Rio de Janeiro, a partir de 2012, voltadas para a inserção profissional docente. Participaram, como sujeitos, professores ingressantes na rede de ensino, gestoras que atuavam no nível central e diretoras de escolas. A coleta de informações foi realizada por meio de consulta a documentos, entrevistas e questionário. O diálogo teórico se deu, principalmente, com Gatti, Barreto e André, Imbernón e Marcelo Garcia. Analisou-se a institucionalização da Escola de Formação do Professor Carioca Paulo Freire, responsável pela implementação dessas ações. Além disso, buscou-se compreender as concepções norteadoras da proposta implementada. Os dados permitiram analisar a organização da instituição, assim como compreender a implementação da proposta. Constatou-se que, na sua curta historicidade, essa institucionalização passou
Universidade Federal do Rio de Janeiro. Rio de Janeiro, Rio de Janeiro, Brasil. E-mail: mgcanascimento@gmail. com; <http://orcid. org/0000-0002-6334-4121>.

II Doutora em Educação pela Pontifícia Universidade Católica do Rio de Janeiro (PUCRJ). Rio de Janeiro, Rio de Janeiro, Brasil.

III Universidade Federal de Minas Gerais (UFMG). Belo Horizonte, Minas Gerais, Brasil. E-mail: mariafloresufrj@gmail.com; $<$ http://orcid.org/0000-00025268-645X >.

IV Doutora em Educação pela Universidade Federal de Minas Gerais (UFMG). Belo Horizonte, Minas Gerais, Brasil.

v Instituto Nacional de Educação de Surdos (Ines). Rio de Janeiro, Rio de Janeiro, Brasil. E-mail: Yrllaribeiro22@yahoo. com.br; <https://orcid. org/0000-0003-4762-9343>.

vI Doutora em Educação pela Universidade Estadual de Campinas (Unicamp). Campinas, São Paulo, Brasil. 
pelo cruzamento de projetos e normatizações que evidenciaram disputas em torno de diferentes perspectivas de formação docente. Os principais achados da pesquisa apontaram que a formação básica oferecida aos docentes, ainda durante o processo seletivo, era a principal ação de formação voltada para os ingressantes e que a proposta de tutoria, apesar de ter sido iniciada, não teve o alcance desejado e foi descontinuada. A pesquisa apontou ainda que o desafio maior era garantir o assentamento de uma política de formação docente mais sistemática e permanente.

Palavras-chave: formação continuada do professor; indução profissional; professores iniciantes; políticas docentes.

\section{Abstract \\ Professional insertion policies of the municipal educational system of Rio de Janeiro: a proposal on the move}

This article presents the results of a research on the propositions of the municipal education system of Rio de Janeiro, as of 2012, targeting the professional insertion of teachers. Those taking part in the research were: as subjects, teachers newly-admitted to the education network; managers operating in the center of the system; and principals. Data collection happened through interviews, questionnaires, and consultation of documents. The theoretical dialogue involved mainly readings of Gatti, Barreto and André, Imbernón, as well as Marcelo Garcia. The institutionalization of the Escola de Formação do Professor Carioca Paulo Freire - responsible for implementing said propositions - was analyzed. Moreover, we sought to understand the main concepts behind the implemented proposal. Data allowed an analysis of the management of the institution, as well as it clarified the implementation of its proposal. It was verified that, in the few years it operated, this training institution has faced the overlapping of projects and rules that revealed a disagreement regarding different points of view on teacher training. This research's main findings reveal that the basic training offered to teachers, still within the selection process, was the main training newcomers got; however, although initiated, it lacked the intended outreach and was discontinued. The research also indicates that the biggest challenge was to ensure that a more systematic and permanent teacher-training policy would be established.

Keywords: continuing teacher training; professional insertion; initial teachers; teaching policies. 


\section{Resumen}

\section{Políticas de inserción profesional en la red municipal de enseñanza de} Río de Janeiro: una propuesta en movimiento

Este artículo presenta los resultados de una investigación que analizó las acciones propuestas por la red municipal de enseñanza de Río de Janeiro, a partir de 2012, centradas en la inserción profesional docente. Participaron, como sujetos, profesores que ingresaron a la red de enseñanza, gerentes que actuaban en el nivel central y directoras de escuelas. La recolección de informaciones se realizó mediante consulta de documentos, entrevistas y cuestionarios. El diálogo teórico tuvo lugar, principalmente, con Gatti, Barreto y André, Imbernón y Marcelo Garcia. Se analizó la institucionalización de la Escuela de Formación del Profesor Carioca Paulo Freire, responsable de la implementación de estas acciones. Además, se buscó comprender las concepciones orientadoras de la propuesta implementada. Los datos permitieron analizar la organización de la institución, así como comprender la implementación de la propuesta. Se constató que, en su corta historicidad, esta institucionalización pasó por el cruzamiento de proyectos y normatizaciones que evidenciaron disputas en torno a diferentes perspectivas de la formación docente. Los principales hallazgos de la investigación indicaron que la capacitación básica ofrecida a los profesores, incluso durante el proceso de selección, era la principal acción de capacitación dirigida a los recién llegados y que la propuesta de tutoría, a pesar de haberse iniciado, no tuvo el alcance deseado y fue descontinuada. La investigación también señaló que el mayor desafío era asegurar el establecimiento de una política de educación docente más sistemática y permanente.

Palabras clave: formación continua del profesorado; inducción profesional; profesores principiantes; políticas de enseñanza.

\section{Introdução}

Este artigo discute resultados de uma pesquisa que buscou analisar as ações propostas pela rede municipal de ensino do Rio de Janeiro, a partir de 2012, voltadas para a inserção profissional de professores que iniciavam suas carreiras. ${ }^{1}$

Analisa a institucionalização da Escola de Formação do Professor Carioca Paulo Freire (EPF) na perspectiva das gestoras que a conduziam no ano de 2015, quando o trabalho de campo foi realizado. Busca, ainda, compreender o processo de implementação e as concepções norteadoras da proposta de formação docente em desenvolvimento.

Partindo do reconhecimento da importância de ações institucionalizadas de apoio e acompanhamento aos professores em início de carreira (Gatti; Barreto; André, 2011) e da constatação da carência de programas sistêmicos

\footnotetext{
A pesquisa foi desenvolvida de 2014 a 2017 e foi submetida ao Comitê de Etica da Plataforma Brasil sob o número 39310914.4.0000.5582, obtendo parecer favorável datado de 16 de dezembro de 2014.
} 
Nome dado, na época em que a pesquisa foi realizada, a um curso que se constitui em uma etapa do concurso para o ingresso na rede, oferecido aos candidatos que foram aprovados na prova escrita. de integração de professores principiantes (Imbernón, 2006), a pesquisa privilegiou a investigação da experiência do município do Rio de Janeiro na implementação, a partir de 2012, de uma política de formação voltada para os professores que ingressam na rede. Essa proposta, anunciada pela gerência do ensino fundamental, em entrevista que nos foi concedida para pesquisa anterior, incluía a criação da EPF, responsável, a partir de então, pela formação em serviço dos professores e pelo curso "Formação Básica"², bem como pela criação de um sistema de tutoria para o acompanhamento dos ingressantes nas escolas.

Tendo essas ações como foco, o caminho metodológico orientou-se no sentido de conhecer as intenções e os princípios dessas ações, a própria dinâmica de formação implementada, assim como a perspectiva dos sujeitos envolvidos.

Os sujeitos desta pesquisa foram professores ingressantes na rede municipal de ensino do Rio de Janeiro, a partir de 2012, que tiveram como uma das etapas do processo seletivo a formação básica oferecida pela EPF. Além dos professores, também participaram da pesquisa as coordenadoras/ gerentes da EPF, como articuladoras dessas ações de formação, e algumas diretoras de escolas, que receberam esses professores participantes da investigação.

Do ponto de vista dos recursos metodológicos, a coleta de informações foi realizada por meio de consulta a documentos, entrevistas (individuais e coletivas) e questionário. O primeiro passo foi a consulta aos documentos (leis municipais, decretos, resoluções) norteadores das ações formativas da Secretaria Municipal de Educação (SME), a partir de 2012, buscando as concepções que orientaram essas ações. Para a identificação dos possíveis sujeitos da pesquisa, procedeu-se, também, à consulta aos sítios eletrônicos oficiais da SME e às publicações do Diário Oficial do Município do Rio de Janeiro que traziam as relações dos professores convocados para a posse, após terem passado pela formação básica.

Para a coleta de informações sobre a percepção dos professores, um questionário foi aplicado. O questionário on-line foi enviado a 84 docentes, de um universo de 325 professores convocados pela SME entre 2012 e 2015, e respondido por 51 deles. Cabe destacar que esses 84 docentes se encontravam em efetivo exercício no momento do trabalho de campo; eles foram localizados por nós e aceitaram participar da investigação.

As entrevistas foram utilizadas com dupla função: exploratória e como meio de complementar os dados obtidos pelo questionário. Ademais, ocorreram em diferentes momentos e foram coletivas. No início do trabalho de campo, foram realizadas com integrantes do nível central do sistema, gestoras da EPF, tendo por finalidade mapear as ações voltadas para a inserção profissional do docente, desenvolvidas desde 2012, bem como compreender as concepções que orientaram essas ações. No segundo momento, após a aplicação do questionário, objetivaram complementar as informações já obtidas e aprofundar pontos levantados por meio dele. Em um terceiro momento, foram realizadas entrevistas com algumas das diretoras que receberam os professores nas escolas e buscaram levantar 
suas visões acerca destes, do curso de formação básica e da responsabilidade da escola como formadora de docentes.

As entrevistas com as gestoras que atuavam na EPF foram realizadas no espaço dessa instituição e compreenderam um total de quatro informantes: a gerente geral, a gerente de formação continuada, a gerente de formação básica e a sua assistente.

Os cargos de gestão da EPF eram comissionados e estavam ocupados por professoras da rede, indicadas pela secretaria de educação. Todas estavam dispensadas das atividades docentes e se dedicavam com exclusividade à gestão da EPF. A distribuição dos cargos atendia à organização prevista e incluía: uma gerência geral responsável pela coordenação de todas as ações, uma gerência de formação básica e uma gerência de formação continuada.

As entrevistas foram realizadas por meio de adesão voluntária e mediante assinatura do Termo de Consentimento Livre e Esclarecido (TCLE). Todas elas foram gravadas em áudio e transcritas posteriormente. Foram tomados os devidos cuidados relacionados à manutenção da fidedignidade dos dados e, para fins de preservação da identidade das gestoras, foram designadas apenas como "gestoras" no decorrer deste texto.

Discutimos algumas concepções que orientaram as ações da SME voltadas para a inserção profissional e o acompanhamento dos professores em início de carreira. Os dados apresentados provêm da análise documental, tendo como fonte os documentos que regulamentam aquelas ações, e das entrevistas realizadas com as quatro gestoras dos programas desenvolvidos no âmbito da EPF. Como o foco deste artigo está centrado na análise das concepções que orientaram o conjunto de ações implementadas pela SME do Rio de Janeiro, não trazemos os dados construídos com base no questionário aplicado aos professores e nas entrevistas realizadas com professores e diretoras de escolas.

O texto se organiza da seguinte forma: inicialmente, trazemos alguns pontos de partida ancorados em estudos que abordam a formação e a inserção profissional, bem como a análise de políticas docentes voltadas para o início da carreira. Em seguida, apresentamos o processo de criação e implementação da EPF com o intuito de compreender o contexto histórico e político no qual foi instituída. Após essa contextualização, discutimos as concepções que vêm orientando as ações formativas da escola, a partir das perspectivas das gestoras dos programas em questão. Finalmente, trazemos algumas considerações que julgamos pertinentes para uma reflexão sobre a formação de professores, o apoio necessário àqueles que iniciam a carreira e as políticas docentes voltadas para a indução profissional.

\section{Formação e inserção profissional de professores como política docente}

A formação docente constitui uma dimensão significativa do desenvolvimento profissional. Trata-se de um processo contínuo de produção e apropriação de saberes com vistas à afirmação profissional (Imbernón, 
2011; Nóvoa, 1995). Tanto no campo da produção de conhecimento quanto no das políticas educacionais brasileiras, presenciamos, a partir das últimas décadas do século 20, um aumento de atenção direcionada à formação docente.

Na perspectiva das políticas educacionais, esse período foi marcado por um número significativo de reformas curriculares nos cursos de licenciatura, baseadas, sobretudo, nas diretrizes curriculares nacionais para a formação de docentes da educação básica, instituídas a partir de 2001, bem como pelas lutas que se deram em torno da elevação da exigência de formação e titulação para os professores dos anos iniciais do ensino fundamental.

Em relação à produção de conhecimento, André (2013) assinala que, a partir dos anos 2000, houve um crescimento significativo nos estudos sobre formação docente e o enfoque se ampliou da formação inicial para preocupações mais direcionadas aos professores, a seus saberes, suas práticas e suas representações. No entanto, a autora chama a atenção para a evidência de poucas pesquisas relacionadas às políticas docentes e ressalta a importância de tomá-las como objeto de estudo (André, 2013).

De acordo com Gatti, Barreto e André (2011), as políticas docentes são aquelas voltadas para os professores e, nesse sentido, é preciso compreendê-las no contexto das políticas educacionais das quais fazem parte, considerando tanto a referência local como o contexto nacional e internacional.

Fanfani (2007, p. 275-276, tradução nossa) aponta um primeiro pressuposto a se considerar em uma política docente:

Toda política docente deve ser integral. Isso quer dizer que deve contemplar intervenções articuladas em pelo menos três dimensões: no recrutamento e na formação inicial e permanente, nas condições de trabalho (divisão do trabalho pedagógico, carreira, contexto institucional de trabalho etc.) e no sistema de estímulos e recompensas materiais e simbólicos.

Nessa perspectiva, entende-se que a formação profissional compreende uma das esferas das políticas docentes. No que tange à formação continuada, foco de nossos estudos, encontram-se na literatura reiteradas críticas sobre as tendências assumidas pelas propostas e práticas regularmente implementadas pelas redes de ensino. Ressalta-se a predominância de concepções formativas compensatórias, pautadas pela noção de que deveriam suprir carências de conhecimentos dos professores. Tal perspectiva se manifesta na própria terminologia utilizada para designar esse momento de formação: "capacitação", "treinamento", "aperfeiçoamento" (Ferreira; Santos, 2016).

Estudos como os indicados anteriormente ressaltam a importância de compreender a formação continuada articulada à valorização profissional. Essa perspectiva pressupõe fortalecimento da formação e das condições de trabalho, em concomitância, como força motriz para um desenvolvimento profissional cujo horizonte seja a afirmação e a valorização do ofício docente. 
Pensar uma formação comprometida com o desenvolvimento profissional docente implica ressaltar a importância de considerar também as especificidades dos docentes nas diversas fases da carreira. A literatura tem apontado, de forma recorrente, a necessidade de um cuidado especial com os professores iniciantes, dadas as dificuldades que enfrentam no momento da inserção profissional. Estudos (André, 2013; Vaillant, 2013; Garcia, 2008) também demonstram que a falta de apoio nessa fase da carreira pode acarretar o abandono da atividade docente ou a reprodução de práticas educativas tradicionais.

Com base em um trabalho que identificou e analisou políticas docentes no Brasil, implementadas por secretarias estaduais e municipais de educação, Gatti, Barreto e André (2011) ressaltam a escassez de experiências de formação voltadas para o acompanhamento e o apoio aos professores que iniciam na profissão, ou seja, para a inserção profissional.

As autoras destacaram apenas três municípios (Jundiaí-SP, Sobral-CE e Campo Grande-MS) que desenvolviam projetos de formação continuada bem articulados voltados para professores iniciantes. Segundo as autoras, são projetos "com propósitos claros, atividades variadas, coerentes com objetivos, metodologia própria, indicação dos resultados esperados e montagem de uma sistemática de avaliação" (Gatti; Barreto; André, 2011, p. 197).

Além dessas iniciativas, as autoras destacaram três estados da Federação (Ceará-CE, São Paulo-SP e Espírito Santo-ES) que implementaram um processo formativo como uma das etapas do concurso para o ingresso na rede, com vistas a uma preparação prévia para a atuação profissional.

Verifica-se, nessas iniciativas, uma diversidade de ações em torno da formação continuada e da indução profissional, que convergem para as recomendações advindas de estudos internacionais, como o de Vaillant (2013). Baseando-se em revisão de literatura e em intercâmbios realizados no âmbito da América Latina, a autora reitera:

\begin{abstract}
Para que a formação não fique em mera retórica e incida efetivamente nas práticas docentes e nos aprendizados dos estudantes nas escolas, haveria que impulsionar uma série de políticas, entre as quais: o acordo a respeito dos critérios básicos a serem cumpridos durante a etapa de formação, a determinação de requisitos para titulação, os mecanismos de recrutamento, a seleção de formadores e os programas de inserção na docência (Vaillant, 2013, p. 53, tradução nossa).
\end{abstract}

Vemos nas considerações de Vaillant (2013), assim como nas análises sobre os programas de formação continuada e indução profissional feitas por Gatti, Barreto e André (2011), uma tendência a considerar os desafios da condição docente na atualidade e a reivindicar que investimentos formativos sejam articulados à valorização da profissão.

O cenário trazido por esses estudos mostra a relevância do apoio e do acompanhamento dos docentes que iniciam na profissão, o que vem sendo apontado reiteradas vezes pela literatura especializada nos últimos 30 ou 40 anos. 
No bojo dos estudos que se articulam em torno da formação e do trabalho docente, a inserção profissional tem emergido como uma questão importante a ser considerada nas análises relacionadas ao desenvolvimento profissional, principalmente mediante a persistência de deserção na carreira docente nos primeiros anos de exercício profissional. Segundo Nóvoa (2007, p. 14), podemos julgar o nível de profissionalidade de uma profissão exatamente pela maneira como ela cuida dos mais jovens. Para o autor, com frequência o magistério trata mal os jovens professores, negando-lhes "qualquer tipo de apoio", e acrescenta:

Se não formos capazes de construir formas de integração mais harmoniosas, mais coerentes desses professores, nós vamos justamente acentuar nesses primeiros anos de profissão dinâmicas de sobrevivência individual que conduzem necessariamente a um fechamento individualista dos professores (Nóvoa, 2007, p. 14).

Trata-se de uma situação presente em diferentes países, tanto latinoamericanos como europeus e norte-americanos. Diversos estudos (Vaillant, 2013; Garcia, 2008) têm chamado a atenção para esse pouco apoio aos professores iniciantes e ressaltado a importância de institucionalização de ações de acompanhamento e formação dos docentes na fase inicial da carreira.

Tal cenário nos mobilizou a estudar a experiência da SME-RJ com a implementação, desde 2012, de um conjunto de ações voltadas para a inserção profissional.

\section{A Escola de Formação do Professor Carioca Paulo Freire em suas origens}

A EPF foi criada pelo Decreto $n^{\circ} 35.602$, de 9 de maio de 2012. Segundo o que está publicado em seu sítio eletrônico, é um espaço de produção de saberes e práticas pedagógicas para subsidiar o planejamento e a implementação da política de formação do professor carioca (Rio de Janeiro, [s.d.], 2016).

Do ponto de vista de sua localização, a EPF está instalada em um complexo que abriga também a Escola Municipal Rivadávia Corrêa, no centro da cidade do Rio de Janeiro.

No que se refere à sua estrutura organizacional, a escola é assim formada:

Gerência de Formação Básica, que promove ações formativas para professores ingressantes na Rede Pública Municipal de Ensino, como uma etapa do processo seletivo para o ingresso na rede; Gerência de Formação Continuada, que promove ações para os professores em exercício, nas modalidades presencial, semipresencial e à distância; e Centro de Referência da Educação Pública da Cidade do Rio de Janeiro - Anísio Teixeira, que dispõe de importante acervo sobre a história da Educação Pública na Cidade do Rio de Janeiro, possibilitando a produção de estudos e pesquisas que ampliam o processo de formação 
dos professores da Rede Pública Municipal de Ensino do Rio de Janeiro

(Rio de Janeiro, [s.d.] 2016).

Embora a escola tenha sido criada em 2012, a origem do Centro de Referência da Educação Pública da Cidade do Rio de Janeiro - Anísio Teixeira (Crep - AT), que a integra, remete às políticas que buscaram reestruturar o sistema educacional a partir dos anos 1980, em um contexto de redemocratização do País, após 21 anos da ditadura instituída pelo Golpe Civil-Militar de 1964.

Assim, desde o início dos anos 1990, a questão da criação de um centro de memória da educação da cidade do Rio de Janeiro esteve em questão. Segundo Barreto (2014, p. 36), em 1989 foi apresentado ao departamento de cultura da SME uma iniciativa intitulada "Projeto de levantamento de fontes históricas da educação municipal", que preconizava o levantamento parcial dos acervos existentes nas escolas da rede municipal e que deu origem ao Centro de Memória (CM), criado em 1992. A autora assinala que o período de 1989 a 1992 pode ser compreendido como a "primeira fase do Centro que, de uma estrutura de grupo de trabalho, passa ao status de um Centro de Memória, com todo o peso e a responsabilidade que uma instituição desse porte precisaria ter." (Barreto, 2014, p. 37).

A partir daí e até 1996, o CM viveu o que a autora chama de uma fase de retraimento, que pode ser relacionada a alguns fatores, tais como a mudança de governo, a falta de estrutura para o Centro, que funcionava em uma pequena sala da SME, e a falta de consenso sobre a quem caberiam as responsabilidades a ele atribuídas (Barreto, 2014).

Em 1997, a equipe que atuava no CM apresentou uma proposta mais ampla, que incluía a troca do nome de Centro de Memória para Centro de Referência e a indicação da Escola Rivadávia Corrêa como local para sua instalação. Dentre as razões apontadas para essa escolha, está a relevância histórica dessa instituição, a segunda escola profissional feminina do Distrito Federal, que teve sua pedra fundamental lançada, em 1874, por Dom Pedro II.

Nos anos que se seguem, dá-se um longo processo de implantação do Crep e a sua instalação na Escola Municipal Rivadávia Corrêa. A inauguração ocorreu em 2002 e, desde então, até 2008, o Crep teve por função a guarda e o levantamento da memória da educação do município do Rio de Janeiro (Barreto, 2014).

Finalmente, em julho de 2012, a SME inaugurou, no mesmo espaço, a EPF, voltada para a formação de professores municipais. Ficaram também sob sua responsabilidade as ações do Crep, agora Crep - AT, como se pode verificar no Decreto $n^{\circ}$ 35.602, de 9 de maio de 2012:

Art. $1^{\circ}$ Fica criada, na estrutura organizacional da Secretaria Municipal de Educação, a Escola de Formação do Professor Carioca Paulo Freire - E/EFP.

$\S 1^{\circ}$ O Centro de Referência da Educação Pública da Cidade do Rio de Janeiro passa a integrar a estrutura organizacional da Escola de Formação do Professor Carioca Paulo Freire - E/EPF. 


\footnotetext{
Eduardo Paes se elegeu como prefeito da cidade Rio de Janeiro pelo Partido do Movimento Democrático Brasileiro (PMDB) pela primeira vez para o mandato de 2009 a 2012 e foi reeleito pelo mesmo partido para o mandato de 2013 a 2016. Portanto, a EPF foi criada no último ano do seu primeiro mandato.

4 Texto disponível em http:// www.rioeduca.net/blog. php?tag $=$ sme.
}

Apesar da importância desse centro de referência para compreendermos o contexto de criação da EPF, essa instância não se constituiu como objeto da pesquisa que realizamos. Nosso foco foram as ações de formação básica e continuada voltadas para os professores e a criação de um sistema de tutoria destinado aos iniciantes na carreira.

A escola teve como primeira gestora a professora Sônia Mercadante e sua inauguração se deu no âmbito do governo de Eduardo Paes ${ }^{3}$. Referindo-se à inauguração da escola, a então Secretária de Educação, Claudia Costin, assinalou: "o centro de formação tem por objetivo valorizar e capacitar os professores do município do Rio de Janeiro, possibilitando uma formação sólida e continuada nas diversas áreas do conhecimento, atendendo assim as necessidades dos alunos da Rede" ${ }^{4}$.

No que se refere à estrutura organizacional interna, a EPF possui uma equipe gestora composta por uma gerente geral e sua assistente e uma gerente e uma assistente para cada uma de suas três gerências (a de formação básica, a de formação continuada e a do Crep - AT), conforme o que se lê no referido decreto, que cria esses cargos e define suas competências. Em visita realizada pela equipe de pesquisadores, pudemos constatar que essa estrutura organizacional estava vigente em 2015, quando da realização das entrevistas.

O decreto que cria a EPF enumera as competências de cada uma dessas gerências. De acordo com esse documento, é de competência da gerência de formação básica:

Definir conteúdo e critérios de aprovação no curso de Formação Básica
para ingresso no quadro do magistério; gerenciar, executar e monitorar
o curso de formação básica, pré-requisito para o ingresso no quadro do
magistério; certificar os professores considerados aptos a ingressar na
Rede Pública Municipal de Ensino (Rio de Janeiro, 2012, p. 4).

Assim, fica determinado que a essa gerência cabe, fundamentalmente, planejar e executar um curso a ser oferecido aos candidatos ao magistério da rede municipal de ensino - etapa que integra, a partir de então, o processo seletivo para esse sistema.

No que se refere à gerência de educação continuada, o documento define que é de sua competência:

\footnotetext{
Gerenciar, executar e monitorar programas, projetos e ações de formação continuada dos professores da Rede Pública Municipal de Ensino do Rio de Janeiro; promover o desenvolvimento de processos de formação, por meio da pesquisa, divulgação e avaliação, disseminando as boas práticas de gestão e interação pedagógica; implementar a aplicação de tecnologias facilitadoras do processo de formação dos professores; realizar estudos e pesquisas que subsidiem o processo de formação continuada dos professores (RJ, DO, 10/05/2012, p. 4).
}

Assim, de acordo com o que é estabelecido, todas as ações formativas oferecidas pela SME aos professores, após o seu ingresso no sistema, passam a ser de responsabilidade dessa gerência.

Ainda de acordo com o referido documento, à gerência geral da escola cabe: 
Definir, em conjunto com a Subsecretaria de Ensino, a Política de Formação do Professor da Rede Pública Municipal de Ensino do Rio de Janeiro; dimensionar as necessidades de desenvolvimento e capacitação dos professores; planejar e supervisionar o curso de Formação Básica, etapa do processo de seleção dos professores candidatos a ingressarem na Rede Pública Municipal de Ensino do Rio de Janeiro; planejar e implementar a Política de Formação do Professor, contemplando ações de formação continuada para os professores em exercício, nas modalidades presencial, semipresencial e a distância; avaliar o processo de Formação do Professor; estabelecer parcerias com organismos nacionais e internacionais de referência em Educação; propor parcerias com agentes financiadores para captação de recursos financeiros na área de formação do professor; aplicar a legislação referente à concessão de licença para estudos (Rio de Janeiro, 2012, p. 4).

Considerando, como Flôr (2007), que a formação continuada de professores vem ganhando diferentes designações, de acordo com o caráter político que a embasa, é possível identificar, no discurso oficial da SME, termos importados de uma lógica empresarial, o que aponta para uma determinada concepção de educação. A esse respeito, Barreto (2014, p. 46) salienta:

A política curricular do governo Eduardo Paes surge num cenário nacional e internacional de globalização econômica, cultural e política, marcado pela universalização de modelos de reformas dos sistemas educacionais, denominados por Hypólito (2008) por estandardizações globais.

As expressões "gerência", "competência" e "capacitação", encontradas tanto no discurso da secretária de educação quanto no Decreto $\mathrm{n}^{\circ}$ 35.602/2012, constituem evidências de uma transposição da lógica do mercado para o campo da educação.

\section{Uma perspectiva de formação de professores em movimento}

Ao triangular os depoimentos das gestoras entrevistadas com a análise da institucionalização da EPF, via documentos e estudos, evidenciou-se os entremeios do processo de implementação de uma política de formação docente e as perspectivas que acenam nesse contexto.

Conforme visto anteriormente, a EPF se configura como espaço de definição de uma política de formação do professor da rede municipal, em conjunto com a subsecretaria de ensino. Portanto, tem um sentido de polo difusor e dinamizador do processo de formação e não se restringe apenas a um espaço físico de abrigo das ações de formação.

Trata-se de um espaço que propõe conceber um tipo de formação de professores cujas características são marcadas tanto pelo contexto institucional mais amplo quanto pelas pessoas que atuam na gestão desse processo. As marcas iniciais da instalação dessa escola evidenciam traços economicistas na produção dessa política de formação, seja por uma organização administrativa com clara racionalidade gerencial, seja pela força de parcerias com instituições privadas na condução de programas e projetos. 
Em termos de estrutura e operacionalização previstas formalmente, pode-se compreender que a institucionalização desse espaço é significativa na constituição de uma política docente na rede municipal do Rio de Janeiro.

Esse processo se faz no contexto de uma mudança importante na carreira docente, no âmbito dessa rede de ensino, que passa a admitir os docentes para uma jornada de trabalho de 40 horas semanais. Essa condição os coloca em situação de ocupação em tempo integral na rede e ressignifica as condições de trabalho, rompendo com a existência de jornada dupla e até tripla em escolas de redes de ensino distintas, situação comum para muitos docentes da educação básica brasileira. Além disso, tal proposta atende às orientações nacionais, como exposto na Resolução CNE/CEB n ${ }^{\circ}$ 02/2009, que fixa as diretrizes nacionais para os planos de carreira dos profissionais do magistério, propondo, em seu artigo $4^{\circ}$, uma jornada, preferencialmente em tempo integral, de no máximo 40 horas semanais.

De acordo com os relatos, a implementação de uma formação básica, com característica seletiva, ou seja, como uma etapa do concurso de acesso à rede, assim como a previsão de uma política de formação continuada estão articuladas às mudanças na carreira docente. Evidenciam a emergência de uma política docente e uma preocupação em qualificar o processo de recrutamento dos professores, o que está de acordo com análises que apontam a relevância de se estabelecer diretrizes consistentes nos concursos públicos para docentes (Gatti; Barreto; André, 2011).

No entanto, o contato com a equipe de gestão foi demarcado por um discurso de transição entre o projeto inicial da EPF e a busca de afirmação de uma proposta de formação, numa perspectiva diferenciada daquela que marcou o início de suas atividades. Os contornos dessa proposta são explicitados nos depoimentos, sempre ancorados numa demarcação de que estão vivendo um momento "híbrido" e "transitório", caracterizado por um processo de "mexidas", "ampliação", "alinhavo" de uma proposta de formação docente.

Nesse sentido, vemos nos depoimentos das gerentes da EPF um esforço para organizar uma política de formação continuada dos docentes:

\begin{abstract}
Na verdade, o desafio hoje, primeiro, é criar uma política de formação continuada em serviço, e o segundo, eu acho que além de você alinhar e criar uma política é você criar um sistema de formação. Então, nós hoje estamos trazendo para a escola... diversos tipos de formação. (...) O nível intermediário que seriam as coordenadorias, e hoje nós temos onze coordenadorias que se organizam em todo território da cidade do Rio de Janeiro, e a gente tem a própria escola como lócus de formação que é um grande desafio nosso de retornar essa conversa e essa discussão a partir da formação do coordenador pedagógico como grande formador desses professores na escola. (Gestora).
\end{abstract}

Podemos perceber que há uma intenção de direcionar a política de formação continuada de maneira descentralizada e focalizada na escola, tendo como principal interlocutor o coordenador pedagógico.

Verifica-se, nessa perspectiva, a busca de uma articulação entre finalidades e abordagens para a proposta formativa dos professores, o que 
acena para a superação de uma das fragilidades apontadas por Gatti, Barreto e André (2011) na investigação realizada: a ausência de uma articulação clara e coerente nos projetos de formação desenvolvidos pelas secretarias de educação.

Contudo, as intencionalidades anunciadas pela gerente estavam situadas em um contexto peculiar de gestão, pois todo o processo de produção dessa política estava assentado em um curto tempo de existência da própria EPF (apenas três anos) e já com uma ruptura em sua coordenação, visto que a gerência em atuação na data da entrevista (2015) estava no cargo há apenas um ano e meio. Somava-se a essa condição a possibilidade de encerramento do governo vigente na prefeitura no ano de 2016, devido às eleições municipais, situação que provocava dúvidas e inseguranças sobre o projeto a ser alçado e os alcances de resultados no curto tempo de governo restante.

Explicitamente, a afirmação de um momento de transição é evidenciada nas recomposições e mudanças de algumas ações que estavam planejadas e até mesmo sendo promovidas pela escola. Entre elas, estava uma reformulação, ainda em estruturação, do curso de formação básica.

De acordo com Silva (2015), o curso de formação básica, em 2013, tinha uma proposta curricular que incluía quatro áreas temáticas: mídias e novas tecnologias, oficinas temáticas e materiais pedagógicos, orientação curricular e oficinas Aula Nota 10, baseadas no livro Aula Nota 10: 49 técnicas para ser um professor campeão de audiência, de Doug Lemov. A carga horária total era de 80 horas, compreendendo duas semanas, de $8 \mathrm{~h}$ às $17 \mathrm{~h}$. O participante recebia uma bolsa-auxílio no valor de $50 \%$ do vencimento inicial do professor para custeio de despesas com a participação obrigatória no curso (Rio de Janeiro. SMA, 2012).

Segundo as gerentes entrevistadas, a primeira mudança seria a redução da carga horária de 80 para 16 horas, restando outras 64 horas para serem cursadas após a posse. O curso, que tinha a duração de dez dias, passou a durar dois dias, o que impôs a redução da bolsa-auxílio de 50\% para $10 \%$ do vencimento inicial de um professor da rede, e a redução do conteúdo abordado, que passava a ter como principal foco a organização e o funcionamento do sistema. Tais mudanças foram anunciadas a partir da avaliação das ações por parte da equipe gestora e a percepção da necessidade de outro formato para o curso. Contudo, como o curso de formação básica estava previsto na legislação que normatizava o concurso ainda vigente, as mudanças somente poderiam ser aplicadas aos novos concursos públicos. Essa mudança se efetivou na última edição ocorrida em 2016.

A formação básica assumia um caráter seletivo, trabalhando com os aspirantes a professores da rede municipal e apontando os aptos e não aptos à prova prática, com base na frequência de, no mínimo, $90 \%$ do curso. $\mathrm{O}$ formato inicial, no âmbito de um processo seletivo, pôde ser visto como um desperdício de recursos públicos, dado que nem todos os que participaram ingressaram no sistema - essa percepção foi explicitada inclusive por algumas professoras e diretoras entrevistadas. No novo formato, com parte da formação após a posse, o curso buscava enfrentar parcialmente esse 
problema e se constituir como uma ação voltada, de fato, para a inserção profissional. É o que anunciaram duas das gestoras entrevistadas:

E acredito muito nisso, nessa formação inicial, pós, o momento da posse. "Eu tomei posse, eu preciso me fortalecer um pouco mais antes de entrar e ao entrar na sala de aula eu tenho a minha formação continuada".

A gente está num modelo híbrido, porque lá no plano de cargos e salários diz que a etapa 3 do concurso é o curso da escola de formação. A gente queria transportar esse curso para a primeira semana dele depois da posse... A gente acha que isso tinha que compor parte do estágio probatório dele... Aí a conversa e a formação ganham uma outra dimensão potencializada e depois, a gente dilui essa questão ao longo de três anos, com acompanhamento.

As inquietudes e os apontamentos sobre as possibilidades de mudanças no curso de formação básica mostravam, por um lado, uma questão econômica, e, por outro, uma readequação na concepção inicial. Ao mudar seu caráter de mecanismo de seleção para incidir sobre a formação do professor já inserido na rede municipal, esse dispositivo ganharia outras finalidades e passaria a ser uma formação voltada para a qualificação do processo de inserção dos professores, ou seja, uma ação voltada à indução profissional.

No entanto, segundo essas gestoras, uma formação para os professores iniciantes, nessa perspectiva, constituía um projeto ainda em definição, que enfrentava desafios, organizacionais e políticos, em seu processo de implementação.

Uma segunda mudança em andamento se referia ao sistema de tutoria, que fora criado para o acompanhamento dos ingressantes, pelo prazo de um ano, no âmbito das escolas, e estava regulamentado pela Resolução SME $n^{\circ} 1.196$, de 2 de agosto de 2012.

Embora regulamentado e implantado, o sistema de tutoria enfrentava dificuldades de diversas ordens e também passava por mudanças em sua proposta. As gestoras expuseram os seguintes enfrentamentos no que se refere a essa ação:

Tem instituída a tutoria de professores novos (...) professor que tem até três anos, ele tem direito a receber um professor tutor. Qual é a função desse professor tutor? Ajudá-lo nas questões de como se constitui professor, nas demandas emergentes... Bom, isso na concepção de como foi idealizado. Existem aí discussões, por exemplo, como eu, que penso que isso tem muito a ver com o coordenador pedagógico, o diretor da escola e o próprio grupo de professores.

... você precisa ter um professor que tem uma carga horária que ele possa se dedicar... ele pode estar tutorando de quatro a seis... Se você contar que você tem mais de mil professores novos... Você acha dentro da rede, quem tenha a carga horária disponível para fazer isso: no máximo, vinte professores. E aí quando você pensa que, tudo bem, que ele quer... Mas ele pode? Ele é o cara que pode dar alguma contribuição teórica, metodológica para aquele professor? Aí você faz uma seleção... Aí você trabalha com 14. Aí 14, atendendo quatro a seis professores, 
você já multiplicou e chegou na sua conclusão de que o atingimento não é o que o programa propõe.

De acordo com as gestoras, os tutores na proposta original eram professores da rede que podiam acompanhar o professor iniciante, independentemente de atuar na mesma escola, bastando terem disponibilidade de carga horária, mínimo de dez anos de regência de turma e terem passado por um processo de seleção. No entanto, as dificuldades enfrentadas, como se pode observar, abarcavam desde questões de infraestrutura até divergências quanto às concepções acerca da proposta. Os depoimentos das gestoras apontavam para a percepção de que seria mais viável trabalhar esse acompanhamento a partir da equipe da própria escola em que o professor estivesse inserido, o que apontava mais uma vez para um movimento de reformulação da proposta.

Além dessa insuficiência na capacidade de atendimento, as gestoras também ressaltaram a necessidade de aprimoramento em relação à proposta de atuação do tutor, pois precisariam criar processos de acompanhamento desse trabalho, no sentido de qualificar a mediação, o acolhimento e o acompanhamento do professor ingressante. No entanto, a viabilidade da proposta parecia ser mínima em sua capacidade de alcançar a população de professores iniciantes, no contexto de uma rede cuja abrangência, em termos de instituições escolares, professores e alunos atendidos, coloca-a como uma das maiores na América Latina. ${ }^{5}$ Essa característica foi bastante ressaltada pelas gestoras, que expressavam preocupação e desejo de dar conta de uma perspectiva de formação condizente com o porte da rede.

No âmbito da formação continuada, posterior à inserção profissional, os depoimentos também apontaram mudanças. Foram relatadas ações voltadas para a regulação de auxílios para a formação em nível de mestrado e doutorado, outras para organização e execução de cursos e palestras destinados a determinados grupos de docentes e para o monitoramento e a mediação de projetos apresentados e desenvolvidos por parceiros. Algumas dessas parcerias eram desenvolvidas com empresas privadas, outras com instituições culturais, como o Museu de Arte do Rio, e outras ainda com programas do Governo Federal, como o Pacto Nacional pela Alfabetização na Idade Certa (Pnaic). O que se constatou foi que os projetos desenvolvidos em parceria com as empresas eram projetos pontuais, focalizados e de pouco alcance em termos de população atendida. Por outro lado, o Pnaic, mais contínuo, foi considerado pelos professores que participaram da pesquisa como o mais efetivo no que se refere à contribuição para a prática docente cotidiana.

Além dessas ações de formação continuada, a equipe da EPF desenvolvia, em 2015, o projeto "Escola em Foco", que abarcava 400 escolas da rede. Nele, a equipe da escola realizava um monitoramento do trabalho pedagógico, considerado como uma gestão colaborativa dos processos educativos, junto às equipes escolares, com o fito de garantir práticas pedagógicas exitosas e reduzir o abandono e a reprovação escolar (Rio de Janeiro, 2015, p. 42). As escolas atendidas eram selecionadas em função
São 1.463 unidades escolares de ensino fundamental e educação infantil, 40.324 professores e 654.454 alunos atendidos (Rio de Janeiro. SME, 2015). 
dos resultados negativos nas avaliações externas e cada uma recebia um professor da rede que passava a atuar como mediador no processo de acompanhamento da gestão da escola.

As descrições das funções atribuídas ao professor mediador nesse projeto indicavam que se tratava de mais um programa de gestão e monitoramento de dados e de estabelecimento de planos de ação. Nessa perspectiva, a formação continuada se constituía mais como um recurso para o alcance de melhores resultados do que como uma proposta com finalidades educativas mais amplas, capaz de articular dimensões da prática pedagógica com o fortalecimento da profissionalidade docente e dos projetos político-pedagógicos das escolas, numa perspectiva crítica e democrática.

Entretanto, os relatos das gestoras apontavam também um momento híbrido. As gestoras reconheciam que a criação da EPF foi um marco importante para o estabelecimento de uma política de formação continuada no âmbito da rede, mas buscavam, nesse momento, uma afirmação no sentido de estabelecer um projeto que deslocasse as escolas de um lugar meramente subsidiário das ações de formação para uma perspectiva mais ativa de concepção e gestão de processos formativos.

Os esforços e as expectativas estavam voltados para um projeto que seria lançado, possivelmente ainda em 2015, cujo foco seria a formação dos coordenadores pedagógicos, uma vez que viam neles a possibilidade de pensar uma formação a partir das próprias escolas.

A proposta de um projeto com foco nos coordenadores pedagógicos das escolas acenava para uma perspectiva que reconhecia a escola como espaço privilegiado para a promoção da formação continuada dos professores, na linha do que escreveu Nóvoa (1992, p. 17): "falar de formação de professores é falar de um investimento educativo dos projetos de escola", ou seja, é considerar a escola como referência e os professores como protagonistas na constituição desse processo. No entanto, essa escolha, por si só, não é suficiente para romper com uma concepção de formação pautada em orientações economicistas, que racionalizam os processos de formação, transformando os docentes em meros consumidores de conhecimentos difundidos por agentes externos às suas práticas.

Evidenciava-se, em 2015, um movimento na direção de uma formação mais contextualizada, com ajuda mútua entre formandos e uma ligação forte com a situação de trabalho (Nascimento, 1996), o que poderia favorecer a articulação entre a promoção de aprendizagens dos alunos e o fortalecimento da profissionalidade docente e do projeto pedagógico da escola.

Essas reflexões evidenciam a dimensão político-pedagógica que uma proposta de formação continuada de professores pode assumir no contexto educativo. Na experiência analisada, ressaltamos a grande complexidade a ser considerada em sua consolidação, tanto pelo tamanho de rede de ensino como pelas disputas políticas em torno das concepções que orientam as propostas, sobretudo quando estão ligadas a governos que podem não se manter no poder. 


\section{Considerações finais}

O estudo do percurso de institucionalização da EPF possibilita entender um movimento em torno da instalação de uma política de formação docente oficializada no âmbito da rede municipal do Rio de Janeiro e acena para a complexa trama que perpassa esse processo.

Na sua curta historicidade, as marcas de institucionalização passam pelo cruzamento de projetos e normatizações que evidenciam disputas em torno de perspectivas que buscam tomar forma no terreno da política docente no contexto carioca.

Ao percorrer e analisar os entremeios da implementação da escola como espaço de formação docente dessa rede, considera-se que há um esforço para alargar e avançar em relação ao projeto inicial. Esse movimento ocorre em torno de uma afirmação da proposta como uma política propriamente dita, que possa alçar um projeto e viabilizá-lo, considerando as especificidades da rede de ensino.

O desafio maior é garantir o assentamento desse espaço, não apenas na política docente, mas na política educacional do município. Conforme aponta Gatti (2011), é relevante a constituição das propostas de formação no campo da política docente, compreendida dentro do escopo de uma política de Estado a ser dimensionada para além de programas e projetos fugazes, assim como de tendências dicotômicas ou binárias.

Nessa perspectiva, uma fragilidade manifesta é a rotatividade observada na gestão dos projetos e a personificação desse processo, uma vez que se trata de um projeto que seria de longo prazo, mas que está sob a coordenação de gestores que trabalham com a periodicidade de um governo, delimitado pelo tempo das eleições municipais.

Uma participação maior da sociedade e, principalmente, dos docentes e de suas representações sindicais na implementação de uma política de inserção profissional e de legitimação da EPF poderia ser uma possibilidade de ruptura com a implementação centrada nas pessoas, propiciando, assim, a ampliação da dimensão pública da política docente e educacional.

Nesse sentido, o próprio esforço de criar novas perspectivas de abordagens da formação continuada, em termos de concepções e metodologias, seria favorecido. Mesmo considerando as escolas como lugares de formação e os seus coordenadores pedagógicos como mediadores, tal como acenavam, resta ainda estabelecer como serão tratadas as interações e as articulações entre saberes docentes individuais e coletivos, as especificidades dos projetos político-pedagógicos das escolas e o apoio institucional para a consolidação desse processo.

Se há certo consenso sobre a necessidade de promover a formação continuada dos professores, vemos nas cenas descritas, a partir da curta experiência da EPF, que as finalidades atribuídas a essa formação podem ser muito distintas e reger formas de tratamento da docência nem sempre adequadas ao fortalecimento profissional em suas diversas dimensões.

Assim, as análises desenvolvidas ao longo deste artigo permitem considerar que a formação continuada deve se constituir como um direito 
dos docentes, implicando a necessidade de institucionalização de condições objetivas para essa formação, assim como a oferta de formação condizente com os pressupostos políticos e pedagógicos defendidos pelo coletivo de professores ao qual se destina a formação.

\section{Referências}

ANDRÉ, M. Políticas de apoio aos docentes em estados e municípios brasileiros: dilemas na formação de professores. Educação em Revista, Curitiba, n. 50, p. 35-49, dez. 2013.

BARreto, S. Centro de Referência de Educação Pública do Município do Rio de Janeiro - CREP: uma análise do Prêmio Anísio Teixeira (2001 2008). 2014. 145 f. Dissertação (Mestrado em Educação) - Universidade Federal do Rio de Janeiro (UFRJ), Rio de Janeiro, 2014.

BRASIL. Ministério da Educação (MEC). Conselho Nacional de Educação (CNE). Câmara de Educação Básica (CEB). Resolução nº 2, de 28 de maio de 2009. Fixa as Diretrizes Nacionais para os Planos de Carreira e Remuneração dos Profissionais do Magistério da Educação Básica Pública, em conformidade com o artigo $6^{\circ}$ da Lei $\mathrm{n}^{\circ} 11.738$, de 16 de julho de 2008, e com base nos artigos 206 e 211 da Constituição Federal, nos artigos $8^{\circ}$, § $1^{\circ}$, e 67 da Lei $\mathrm{n}^{\circ} 9.394$, de 20 de dezembro de 1996, e no artigo 40 da Lei $n^{\circ} 11.494$, de 20 de junho de 2007. Diário Oficial da União, Brasília, DF, 29 maio 2009. Seção 1, p. 41-42.

FANFANI, E. T. La condición docente: análisis comparado de la Argentina, Brasil, Perú y Uruguai. Buenos Aires: Siglo XXI, 2007.

FERREIRA J, SANTOS J. Modelos de formação continuada de professores: transitando entre o tradicional e o inovador nos macrocampos das práticas formativas. Cadernos de Pesquisa, São Luís, v. 23, n. 3, set./dez. 2016 .

FLÔR, D. C. Formação continuada de professores na escola: qual o lugar da infância? 2016. 109 f. Dissertação (Mestrado em Educação) Universidade Federal de Santa Catarina (UFSC), Santa Catarina, 2016.

GATTI, B.; BARRETO, E.; ANDRÉ, M. Políticas docente no Brasil: um estado da arte. Brasília: Unesco, 2011.

GARCIA, C M. Políticas de inserción a la docencia. In: GARCIA, C. M. (Coord.) El profesorado principiante: inserción a la docencia. Barcelona: Octaedro, 2008. 
IMBERNÓN, F. La profesión docente desde el punto de vista internacional: que dicen los informes? Revista de Educación, Madrid, n. 340, p. 41-49, mayo/ago. 2006.

IMBERNÓN, F. Formação docente e profissional: formar-se para a mudança e a incerteza. São Paulo: Cortez, 2011.

NASCIMENTO, M. G. C. A. A escola como espaço de formação continuada de professores: análise de uma experiência. 1996. 132 f. Dissertação (Mestrado em Educação) - Pontifícia Universidade Católica (PUC), Rio de Janeiro, 1996.

NÓVOA, A. Notas sobre formação (contínua) de professores. [S.l: s.n.], 1992. Mimeografado.

NÓVOA, A. Os professores e sua formação. Lisboa: Dom Quixote, 1995.

NOVOA, A. Desafios do trabalho do professor no mundo contemporâneo. 2007. Palestra proferida no SINPRO. Disponível em: <http://www. sinprosp.org.br/arquivos/novoa/livreto_novoa.pdf $>$. Acesso em 03 jan. 2016.

RIO DE JANEIRO (Município). Escola Paulo Freire [Quem somos]. Rio de Janeiro, [s. d.]. Disponível em: <http://epf.rioeduca.net/sobrenos.html>. Acesso em: 03 jan. 2016.

RIO DE JANEIRO (Município). Decreto no 35602, de 9 de maio de 2012. Altera a estrutura organizacional da Secretaria Municipal de Educação - SME. Diário Oficial do Município do Rio de Janeiro, Rio de Janeiro, v. 26 , n. 37, p. 3-4, 10 maio 2012.

RIO DE JANEIRO. Secretaria Municipal de Administração (SMA). Edital SMA $n^{\circ} 159$, de 16 de outubro de 2012. Regulamenta o concurso público para provimento de cargo de professor I - Língua Portuguesa, do quadro permanente de pessoal do município do Rio de Janeiro, no âmbito da Secretaria Municipal de Educação. Rio de Janeiro, 16 de outubro de 2012. Disponível em: <https://arquivos.qconcursos.com/regulamento/ arquivo/19933/prefeitura_de_rio_de_janeiro_rj_2012_professor_lingua portuguesa-edital.pdf >. Acesso em: 26 nov. 2019.

RIO DE JANEIRO. Secretaria Municipal de Educação (SME). Resolução SME $\mathrm{n}^{\circ}$ 1.196, de 2 de agosto de 2012. Regulamenta o Sistema de Tutoria direcionado aos profissionais docentes. Diário Oficial do Rio de Janeiro, 8 ago. 2012. Disponível em: <http://smaonline.rio.rj.gov.br/ legis_consulta/42705Res\%20SME\%201196_2012.pdf>. Acesso em: 26 nov. 2019. 
RIO DE JANEIRO. Secretaria Municipal de Educação (SME). Educação em números. [s.d.] Disponível em: <http://www.rio.rj.gov.br/web/sme/ educacao-em-numeros $>$. Acesso em: fev. 2015.

SILVA, C. M. Estratégias de formação para o trabalho docente no município do Rio de Janeiro: o papel da Escola de Formação Professor Paulo Freire. 2015. Monografia (Graduação) - Faculdade de Educação, Universidade Federal do Rio de Janeiro, Rio de Janeiro, 2015.

VAILLANT, D. Las políticas de formación docente en América Latina. Avances y desafíos pendientes. In: POGGI, M. (coord.). Políticas docentes: formación, trabajo y desarrollo profesional. Buenos Aires: IIPE UNESCO, 2013.

Recebido em 11 de setembro de 2018.

Aprovado em 9 de agosto de 2019. 